\title{
Existe um antepredicativo pático? Uma possível leitura do percurso heideggeriano
}

\author{
Chiara Pasqualin \\ Universität Koblenz-Landau \\ Institut für Philosophie \\ chiarapasqualin@hotmail.it
}

\section{Resumo}

Embora o conceito de "antepredicativo" (vorprädikativ) encontre-se apenas duas vezes em Ser e tempo, este qualifica de maneira essencial aquele processo hermenêutico, no qual os existenciais da compreensão, da interpretação e do discurso cooperam para a estruturação do âmbito fenomenal num horizonte de significância. Tal estruturação hermenêutica representa para Heidegger a precondição de cada comportamento teorético-predicativo do Dasein com o ente. Por meio de um trabalho de história conceitual ao longo dos anos vinte, é possível evidenciar que Heidegger estabelece uma equivalência substancial entre o antepredicativo e o hermenêutico. Todavia, desenvolvendo algumas indicações presentes nos textos heideggerianos, podem ser traçados os contornos de uma outra história, na qual o conceito de antepredicativo indica uma dimensão mais profunda do ser humano, que pode ser designada como "pática" ou pré-hermenêutica. Para este fim, parece-me decisivo abordar o conceito de pré-mundano (vorweltlich), introduzido no primeiro curso tido por Heidegger em Freiburg (1919), a análise da angústia em 1929 e, enfim, a figura do "grande silêncio" ( große Stille) nas Contribuições à filosofia.

Palavras-chave: antepredicativo, pático, Heidegger, hermenêutico, linguagem

Abstract: Although the term "pre-predicative" (vorprädikativ) is used only two times in Being and Time, it qualifies in an essential way the hermeneutical process in which the existentials of understanding, interpretation and discourse cooperate to structure the phenomenal field into a meaningful horizon. This hermeneutical function represents for Heidegger the precondition for every theoretical-predicative behaviour of Dasein towards being. By means of a conceptual-historical analysis throughout the Twenties, it is possible to point out that Heidegger considers the domain of the pre-predicative identical to the hermeneutical process. Nevertheless, on the basis of some indications 
that are to be found in Heidegger's writings, we can trace the contours of a different history of the concept of "pre-predicative", in which the latter hints at a deeper dimension of the human being - a dimension that can be designated as "pathic" or "prehermeneutical". To this purpose, it is essential to investigate the concept of "preworldly" (vorweltlich), introduced by Heidegger in his first lecture course, his analysis of anxiety in 1929 and, finally, the image of the "great silence" (große Stille) in the later Contributions to Philosophy.

Keywords: pre-predicative, pathic, Heidegger, hermeneutical, language

\section{O «antepredicativo»: uma introdução}

O conceito de «antepredicativo» (vorprädikativ) ocupa um papel central não somente na primeira fase do pensamento heideggeriano, mas também no âmbito do pensamento da história do $\operatorname{Ser}^{1}$. Nos primeiros cursos proferidos por Heidegger em Freiburg ainda não aparece a palavra «antepredicativo», mas o conceito que será depois designado por esse termo já está delineado nos seus traços essenciais. A noção que nos primeiros cursos de Freiburg antecipa o conceito de «antepredicativo» é aquela de «pré-teorético» (vortheoretisch) ${ }^{2}$. Se bem que os dois conceitos não sejam perfeitamente identificáveis, pode-se afirmar que todo o âmbito daquilo que Heidegger nos anos seguintes definirá como antepredicativo pertence à esfera do pré-teorético ${ }^{3}$. Este último é

${ }^{1}$ Para uma reconstrução completa da presença deste conceito no pensamento de Heidegger e para uma demonstração da sua relevância referimos à introdução ao volume coletivo: Pasqualin e Sforza, 2020: 13-50.

${ }^{2}$ Sobre o conceito de «pré-teorético» veja sobretudo: von Herrmann, 2000.

${ }^{3}$ Tudo o que é antepredicativo - ou seja, tudo o que se refere a uma comprensão (comprensão pré-ontológica constitutiva do Dasein) que ainda não é expressa de forma predicativa - é pré-teorético. O prédicativo é o âmbito da predicação (Prädikation), ou seja, daquilo que Heidegger define como enunciação (Aussage). No curso de 1925/26, no qual Heidegger indroduz pela primeira vez o termo «antepredicativo», ele examina sobretudo dois casos-limites: por um lado, o «ter-de-se-haver com» ainda inexpresso e não temático e, por outro lado, a enunciação categórica (kategorische Aussage), ou seja, a enunciação determinante (bestimmende Aussage). No contexto deste curso, as noções de antepredicativo e predicativo são primeiramente referidas a estes dois comportamentos extremos e exemplificativos: respectivamente, ao comportamento prático-manipulativo ainda não exprimido e à enunciação teorética. O objetivo da análise crítica de Heidegger é, em particular, a predicação na forma teoréticadeterminante - em alguns casos o termo Aussage é utilizado simplesmente como o sinônimo de bestimmende Aussage: por exemplo, quando Heidegger salienta, na fase 
definido, em primeiro lugar, pela sua oposição à atitude teorético-reflexiva, a qual produz um afastamento do viver espontâneo e objetiva o que é experimentado (Heidegger, 1999: 75, 98). Um segundo aspecto caraterístico do pré-teorético é a sua imediata e permanente orientação ao significado, entendido como a função instrumental de algo encontrado em vista do projeto cada vez mais possuído pela vida humana (Heidegger, 1999: 70-73). O préteorético designa assim a dinâmica específica da vida humana, que se move originariamente num processo de compreensão, na qual é elaborado o significado do ente cada vez encontrado. Essa compreensão não é uma reflexão temática, não identifica um comportamento teorético. Ao contrário, é o próprio comportamento teorético - do qual a enunciação (Aussage) é um momento constitutivo $^{4}$ - que é uma modificação, e então uma derivação, daquele primário processo de compreensão ainda não refletido (Heidegger, 1999: 91, 96) 5 .

posterior do seu pensamento, que a poesia «nicht in Aussagen [spricht]» (Heidegger, 1983: 165). Contudo, no curso de 1925/26 Heidegger aponta que há também enunciações não determinantes, feitas «dentro da execução prática» (innerhalb des Verrichtens) (Heidegger, 1999: 157). Estas formas de enunciação pertencem a um âmbito predicativo (num sentido amplo), mas ainda não teorético. Também em Ser e tempo Heidegger menciona que existem várias formas de enunciação: «Entre a interpretação ainda inteiramente encoberta no entender ocupado e o caso extremamente oposto de uma enunciação teórica sobre subsistente, há uma multiplicidade de graus intermediários» (Heidegger, 1977: 210; trad. de F. Castilho, 447). No que segue, assumimos, porém, o predicativo no sentido da enunciação teorético-determinante.

${ }^{4}$ Utilizamos aqui o termo «enunciação» no sentido específico de «enunciação determinante», ou seja, daquela enunciação que modifica o originário «com-quê utilizável do ter-de-fazer» num subsistente (Vorhandenes) «determinado assim-e-assim em sua subsistência» (Heidegger, 1977: 209-210; trad. de F. Castilho, 445-447).

5 Deve-se sublinhar aqui a ambivalência do termo «antepredicativo»: é possível qualificar como antepredicativos tanto o processo ontólogico da compreensão, que é a condição de possibilidade dos vários comportamentos (práticos e teoréticos), quanto determinados comportamentos ônticos (comportamentos não-enunciativos). Neste contexto é decisivo o primeiro, e mais fundamental, sentido de «antepredicativo». Se o antepredicativo indica, neste primeiro sentido, o processo ontólogico da compreensão, pode se qualificar como antepredicativa também a transcendência do Dasein. No curso de 1927 sobre Os problemas fundamentais da fenomenologia Heidegger mostra como os comportamentos ônticos intencionais são fundados na transcendência do Dasein, isto é na prévia compreensão do ser (Heidegger, 1975: 99-101, 230, 444). Esta transcendência é caracterizada, no curso de 1928, como «Urtranszendenz» (Heidegger, 
A primeira ocorrência do termo «antepredicativo» encontra-se, porém, no curso de Marburg de 1925/26 no âmbito de uma análise que antecipa claramente o contexto teórico no qual este conceito é encadeado em Ser $e$ tempo ${ }^{6}$. No curso de 1925/26 Heidegger mostra como a enunciação, com a qual afirmo, por exemplo, que um quadro é preto, pressupõe que o ente-quadro seja já descoberto, isso é, compreensível como algo para escrever, como algo significativo (Heidegger, 1976: 144, 148). O comportamento predicativo da enunciação funda-se, assim, num descobrir prévio, o qual consiste na compreensão do significado do ente 7 . Esta compreensão é explicitamente definida por Heidegger como antepredicativa (Heidegger, 1976: 144), porque é ontologicamente anterior à enunciação e é o que a torna possível (Heidegger, 1976: 145). Esta compreensão identifica o que Heidegger, no mesmo curso de 1925/26, define como «a estrutura hermenêutica fundamental do ser» do Dasein (Heidegger, 1976: 150, nota 6). Pode-se destacar, assim, que desde a sua primeira ocorrência o termo «antepredicativo» se refere ao processo da compreensão, ou seja, ao movimento hermenêutico da vida humana.

Uma caraterização mais detalhada deste processo hermenêutico distintivo do ser humano é oferecida por Ser e tempo. O termo «antepredicativo», que comparece apenas duas vezes em Ser e tempo (Heidegger, 1977: 198, 476), qualifica, todavia, de maneira essencial o processo hermenêutico há pouco mencionado. Heidegger fala explicitamente de um «"como" hermenêutico» (Heidegger, 1977: 210), ou seja, da configuração significativa, na qual algo fenomenal se mostra ao Dasein. Para que algo se mostre como significativo, isto é, como algo hermenêutico ou compreensível, é necessária a atividade conjunta dos existenciais da compreensão (Verstehen), da interpretação (Auslegung) e do discurso (Rede). Por meio destes existenciais o Dasein pode articular o horizonte do que se mostra num contexto de significância, ou seja, numa rede de conexões entre

\footnotetext{
1978: 170). Sendo o que funda os comportamentos intencionais, a Urtranszendenz é mais originária da intencionalidade e pode ser considerada, neste respeito, como préintencional. Deste ponto de vista, o antepredicativo, no primeiro sentido mencionado, pode ser caracterizado como pré-intencional.

${ }^{6}$ Sobre este curso e a tematização do $\lambda$ ó $\gamma$ oৎ aqui conduzida: Volpi, 1992.

${ }^{7}$ O caráter derivado da estrutura predicativa (em relação ao curso de 1925/26) é bem evidenciado por Figal, 2013: 40-51.
} 
significados e possibilidades projetadas. Esta estruturação prévia do dado fenomenal num contexto significativo, que resulta do processo hermenêutico, é a precondição para que o Dasein possa articular e fixar significados na enunciação ${ }^{8}$. Por essa razão, assim como já no curso de 1925/26, o processo da compreensão é definido como «antepredicativo» (Heidegger, 1977: 476) ${ }^{9}$.

Depois de Ser e tempo, o termo «antepredicativo» é utilizado novamente no curso de 1929/30 (Heidegger, 1983: 492-507). Também neste contexto, diferente, em alguns aspectos, daquele de Ser e tempo, o conceito de antepredicativo serve para qualificar o processo hermenêutico distintivo do Dasein, um processo que agora Heidegger define como «formação de mundo» (Weltbildung).

No pensamento heideggeriano mais tardio da história do Ser, embora o termo «antepredicativo» não seja mais utilizado, o conceito mantém a sua importância e está implicitamente presente na abordagem de assuntos centrais do período após a Kehre. Isso é especialmente evidente no que respeita ao pensar (Denken) e ao poetar (Dichten). Estes últimos podem ser considerados como atuações do processo hermenêutico do Dasein, isto é, são modos, nos quais o Dasein opera uma compreensão antepredicativa do Ser e do seu acontecimento. Heidegger insiste em mostrar como o pensar filosófico e a poesia seriam mal-entendidas como conjuntos de enunciações sobre algo subsistente (cf., entre outros: Heidegger, 1997: 268; Heidegger, 2000: 194). Heidegger realça que as afirmações do pensar filosóficos e os versos da poesia

\footnotetext{
${ }^{8}$ Se o antepredicativo (que funda a linguagem predicativa) pertence a um âmbito prélinguístico ou se já é articulado em si de forma linguística é um ponto de controvérsia entre intérpretes. Entre os defensores da primeria tese cf.: Tugendhat, 1976: 104-105 e Dreyfus, 1991. A segunda tese é argumentada, entre outros, por: Apel, 1975: 55; Lafont, 1994. Inkpin (2016) indaga o papel da linguagem em Ser e tempo e mostra como as expressões linguísticas têm, ao mesmo tempo, um sentido pragmático e um sentido apresentativo (presentational). Estes dois sentidos são, no entendimento do autor, fatores que não podem ser reduzidos à função predicativa das proposições. Uma outra questão aberta é aquela concernente ao caráter conceitual ou pré-conceitual do «ter-de-se-haver» antepredicativo com o mundo. Neste respeito, Golem defende que a experiência antepredicativa do mundo é já conceitual (Golob, 2014).

${ }^{9}$ Para um confronto entre Heidegger e Husserl no que diz respeito à interpretação da conexão entre experiência antepredicativa e nível predicativo veja: Vigo, 2012; Costa, 2015 .
} 
têm apenas a aparência de enunciados predicativo-determinantes. Se a enunciação é entendida - como aponta Heidegger - como uma constatação relativa a algo subsistente ${ }^{10}$, a poesia e a filosofia não contêm enunciações, e, deste ponto de vista, podem ser consideradas modos da linguagem antepredicativa. O dizer filosófico e o poético não constatam nem reproduzem uma realidade suposta simplesmente subsistente em frente a nós, mas formam novos significados e são capazes de revolucionar as coordenadas simbólicas, nas quais habitamos. São, portanto, modalidades eminentes de atuação daquele processo hermenêutico, no qual o Dasein está já sempre envolvido de maneira pré-reflexiva.

\section{Indícios para uma releitura histórico-conceitual alternativa}

O objetivo das presentes considerações não é o de detalhar ainda mais as etapas da história do conceito de antepredicativo no pensamento heideggeriano nem o de analisar as suas nuances. O que interessa aqui destacar é a equivalência que Heidegger estabelece de maneira evidente entre o antepredicativo e o hermenêutico. Mostramos de que maneira o próprio Heidegger qualifica explicitamente como antepredicativo o processo hermenêutico da compreensão, no sentido em que este processo é mais originário do que o comportamento teorético-predicativo, isto é, do que um comportamento que objetiva, fixa, constata, mas sempre pressupõe um âmbito ôntico que é já descoberto, enquanto estruturado como significativo.

Contudo, existem no percurso heideggeriano indicações menos explicitas, que permitem traçar uma outra história conceitual, na qual o antepredicativo não designa apenas o hermenêutico, mas também uma dimensão mais originária do ser humano e da maneira do seu existir e do seu estar-exposto ao dado fenomenal. Pretendemos mencionar algumas dessas indicações presentes na obra de Heidegger e mostrar um outro sentido possível de «antepredicativo»: «antepredicativo» como sinônimo de «préhermenêutico» ou «pático». Em particular, no que segue, será esclarecido em qual significado os termos «pré-hermenêutico» e «pático» - termos que não

\footnotetext{
${ }^{10}$ Cf. Heidegger, 1983: 164: «Wenn über Vorliegendes, Vorgefallenes eine zutreffende oder auch nicht zutreffende Auskunft gegeben wird, nennen wir dies eine Aussage. Sie stellt etwas Vorgegebenes fest».
} 
aparecem em Heidegger - podem ser utilizados no âmbito de uma interpretação original dos textos.

A primeira indicação que merece ser considerada é contida no primeiro curso que Heidegger lecionou em Freiburg, em 1919, sobre A ideia da filosofia e o problema da visão do mundo. Neste curso, Heidegger introduz a noção de pré-teorético, da qual já falamos. Ele descreve, em particular, qual é a modalidade mais habitual em que o homem experimenta o que encontra no seu mundo. O filósofo designa esta modalidade com a expressão «vivência mundana (ou do mundo circundante)» (Umwelterlebnis) (Heidegger, 1999: 7073). Trata-se de uma maneira de experienciar os fenômenos na qual aquilo que se encontra se apresenta imediatamente como algo «significativo» (bedeutsam) (Heidegger, 1999: 73) - «significativo» sobretudo para a praxis, para a atuação prática da vida humana. Este algo significativo é também definido como «mundano» (welthaft) (Heidegger, 1999: 73). A «vivência mundana» é, para Heidegger, pré-teorética, ou, antecipando o léxico posterior, antepredicativa.

Contudo, a vivência mundana não é a única modalidade de vivência antepredicativa. Num esquema que Heidegger traça na última sessão do seu curso de 1919, observe-se que Heidegger reconhece também a possibilidade de experimentar algo «pré-mundano» (vorweltlich) (Heidegger, 1999: 219). Se, neste primeiro curso, o «mundano» é explicitamente sinônimo de significativo, é possível interpretar o pré-mundano como algo pré-significativo. O esquema traçado por Heidegger, e as últimas páginas do manuscrito do curso de 1919, mostram, assim, que Heidegger não exclui a possibilidade de que o homem possa experimentar, em momentos de vida de particular intensidade, o dado fenomenal como não-significativo, como algo em que o momento significativo se subtrai a nós. O que caracteriza o pré-mundano é, segundo quanto afirma Heidegger de maneira fragmentária, a sua indiferença em relação ao caráter mundano (Heidegger, 1999: 115) - caráter mundano que já sabemos consistir para Heidegger no caráter significativo. $\mathrm{O}$ algo pré-mundano é, portanto, algo que é indiferente ao significado, ou, em outros termos, algo que é experimentado «independentemente» do significado. Este algo pré-mundano é chamado por Heidegger «o algo originário» (Ur-etwas) e é distinguido do algo mundano (welthaftes Etwas), isto é, do algo significativo (Heidegger, 1999: 219). 
No curso de 1919 Heidegger não oferece, porém, nenhum exemplo para ilustrar esta tipologia de vivência que é pré-teorética, mas ainda não significativa. Nossa hipótese é de ler nesta vivência do pré-mundano a primeira forma em que Heidegger conceitualiza a experiência da angústia (Angst), ${ }^{11}$ que é central sobretudo em Ser e tempo e na lição inaugural de 1929, o que é metafísica? O indício maior que torna legitima esta associação é representado por uma ideia que Heidegger exprime no parágrafo 40 de Ser e tempo. O que acontece na angústia é que o dado fenomenal não tem nenhuma significância. Heidegger escreve que a significância «se perde em si» (sinkt in sich zusammen) e que «o mundo possui o caráter de total insignificância» (hat den Charakter völliger Unbedeutsamkeit) (Heidegger, 1977: 247). Não é descrita aqui precisamente uma vivência de algo pré-significativo no sentido do curso de 1919? A perda de significância daquilo que é experimentado na angústia nos parece prefigurada pela ideia, expressa em 1919, da indiferença ao caráter significativo que caracteriza o algo pré-mundano. Não é somente o aspecto de insignificância ou indiferença ao significado o que permite de interpretar a angústia come um exemplo da vivência do pré-mundano. Parece-nos também relevante o fato de que Heidegger utiliza no parágrafo 40 uma expressão análoga a Ur-etwas: Heidegger escreve que a angústia revela o "“algo" mais originário» (das ursprünglichste „Etwas“) (Heidegger, 1977: 248). Em que consiste este algo originário, ao qual a angústia dá acesso?

Há uma passagem do posfácio a $O$ que é metafísica? que esclarece o que significa para o homem fazer experiência do chamado «algo originário». Heidegger escreve que: «O homem, único entre todos os entes, chamado pela voz do Ser, experimenta a maravilha de todas as maravilhas: isso é, o fato de que o ente é» (Heidegger, 1976a: 307). O algo originário é identificável no fato de que o ente é: é, em outras palavras, o puro fato do ser (Seinsfaktum), o fato de que o ente é algo e não o nada. Deste algo originário o homem faz concreta experiência na condição rara e excepcional da angústia. Ao contrário, o que o homem experimenta habitualmente é - como põe em evidência o parágrafo 33 de Ser e tempo - o «algo como algo» (etwas als etwas) (Heidegger, 1977: 211),

\footnotetext{
${ }^{11}$ Já Kisiel tem sugerido, sem aprofundar mais esta correspondência, que é possível entrever na vivência do pré-mundano uma antecipação da angústia (Kisiel, 1992: 112113).
} 
ou seja, o algo como algo significativo. Este «algo como algo» é o resultado do processo hermenêutico, no qual o Dasein compreende e interpreta o ente de maneira antepredicativa. Mas a experiência habitual do algo enquanto algo não é a única experiência antepredicativa. Na angústia o homem realmente experiencia uma perda de significância, na qual se revela o puro fato de que o ente é. Se, na angústia, o significado do ente torna-se indiferente, abre-se, contudo, a possibilidade de experimentar o puro fato de que algo em geral é manifesto para o homem.

Agora temos que explicar o que acontece ao nível dos existenciais do Dasein para que ele possa fazer experiência do algo originário. Se o mostrar-se de algo significativo é o resultado da atividade do existencial fundamental da compreensão, e se na angústia se verifica uma perda total de significância, isso implica que, nos raros momentos da angústia, a compreensão com a sua função de estruturação hermenêutica não é mais ativa. Deve ser, portanto, o outro existencial fundamental, a Befindlichkeit, responsável do acesso ao algo originário. Compreensão e afetividade são - segundo a nossa leitura - as duas modalidades fundamentais, ${ }^{12}$ pelas quais o Dasein tem acesso ao dado fenomenal. Este dado, porém, se mostra de maneira diferente dependendo da via de acesso, ${ }^{13}$ isto é, dependendo se esta via é a compreensão ou a afetividade. Já dissemos que a compreensão descobre o dado fenomenal como algo significativo. Diferentemente, pode-se argumentar que o chamado «caráter-deabertura» (Erschließungscharakter) da Befindlichkeit (Heidegger, 1977: 182) consiste no fato de que ela dá acesso ao fato do ser, ao dado fenomenal como algo dado e não como algo não dado.

Desta breve consideração emerge qual é a nossa interpretação do conceito de Befindlichkeit. Em primeiro lugar, acentuamos o estatuto ontológico da Befindlichkeit. Em nosso entendimento, a Befindlichkeit não é somente a indicação formal de que o Dasein está sempre numa disposição emotiva. Befindlichkeit não é somente o sinônimo de Gestimmt-sein, do «estaremotivamente-disposto». Concebemos a Befindlichkeit como uma fonte de

12 Heidegger define a Befindlichkeit e o Verstehen como as «duas modalidades constitutivas» nas quais o Dasein é o seu $D a$, ou seja, pode existir numa abertura ao que se mostra (Heidegger, 1977: 177).

${ }^{13}$ Heidegger explica que o ente se mostra de maneira cada vez diferente dependendo da via de acesso (Zugangsart) a ele (Heidegger, 1977: 38). 
experiência, como uma via de acesso que é independente da outra fonte de experiência representada pela compreensão ${ }^{14}$. Normalmente, na nossa experiência habitual, estas duas estruturas atuam juntas: a Befindlichkeit abre originariamente o dado fenomenal, que é articulado de maneira significativa pelo existencial da compreensão. Existem, porém, situações-limite - as vivências do pré-mundano, das quais a angústia é um exemplo - nas quais a compreensão é temporariamente suspensa, de modo que só a Befindlichkeit é ativa o oferece o seu acesso. Consequentemente, nestas situações ônticas, o dado fenomenal não se mostra mais como significativo, mas se manifesta no puro fato do seu ser, além de qualquer significado ${ }^{15}$.

A abertura característica da Befindlichkeit é antepredicativa, mas num sentido diferente do descobrir próprio da compreensão. Não somente a via de acesso da Befindlichkeit é claramente não-teorética, mas é também préhermenêutica. A tarefa específica da afetividade não consiste em articular o horizonte fenomenal num contexto de significância, mas em pôr o homem originariamente em contato com algo em geral. Esta via de acesso préhermenêutica pode também ser designada como «pática». Com esta palavra,

${ }^{14}$ Esta interpretação é parte da tese relativa à primazia ontológica da Befindlichkeit que nós desenvolvemos em vários contextos: para uma exposição sintética desta tese cf. Pasqualin, 2015. Esta tese articula-se em duas subteses: a) a Befindlichkeit é ontologicamente anterior à compreensão; $b$ ) a Befindlichkeit é uma via de acesso autônoma ao dado fenomenal. A compreensão tem a estrutura do «projeto lançado», isto é, é uma abertura que sempre pressupõe algo já dado. Este dado preliminar que a compreensão pressupõe não é simplesmente o «já compreendido», mas algo externo ao mesmo círculo hermenêutico (círculo descrito em Heidegger 177: 197-204). Este algo preliminar é o dado originariamente aberto pela Befindlichkeit. A compreensão pode articular de maneira significativa somente aquele dado que é aberto a priori pela Befindlichkeit (subtese $a$ ). Se a abertura da compreensão não pode ter lugar sem a abertura prévia da afetividade, isso não implica o contrário. A abertura da Befindlichkeit é, em princípio, independente ou autônoma da abertura da compreensão: para que a Befindlichkeit abra o dado fenomenal, não é necessário que a compreensão seja simultaneamente em ato (subtese $b$ ).

15 Defendemos aqui um grau mínimo de realismo a fim de evitar uma completa identificação do real com o produto da atividade projetante do Dasein. $\mathrm{O}$ algo originário é uma realidade independente do sujeito, uma alteridade que o afeta antes de qualquer projeto compreendente. Defender a originariedade deste algo pré-significativo não significa apoiar um realismo ingênuo, mas salvar uma transcendência mínima do fenomenal relativamente à capacidade hermenêutica do sujeito. 


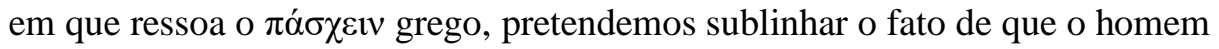
está, por meio da Befindlichkeit, passivamente exposto ao dado fenomenal, é originariamente afetado - affiziert - pelo fato de que algo em geral é.

A angústia é, como já mostramos, uma condição em que o homem experimenta o algo fenomenal pelo único meio da Befindlichkeit e exemplifica, portanto, uma experiência antepredicativa. Esta situação ôntica é caracterizada - como já foi dito - pelo fato de que a compreensão é suspensa, não é ativa. Mas este não é o único aspecto que caracteriza a angústia. Na lição de 1929, Heidegger escreve que a angústia nos corta a palavra e que, nela, cada tentativa de falar-«é» falta (Heidegger, 1976a: 112). No Posfácio a «O que é metafísica?», isso é expresso de maneira ainda mais radical: aqui a angústia é definida como um dos lugares essenciais da «ausência de linguagem» (Sprachlosigkeit) (Heidegger, 1976a: 312). O que significa esta ausência de linguagem? Nós a interpretamos no sentido de que, na angústia, a capacidade de articulação linguística como tal é suspensa. Heidegger escreve que cada tentativa de dizer-«é» falta, o que significa que não é uma certa formulação que se torna impossível, mas toda comunicação linguística, sendo a palavra «é» sempre implícita em cada discurso e proposição. Se, na angústia, é impossibilitada toda comunicação linguística, entendida como expressão de significados, isto implica que deve estar faltando a condição de possibilidade da linguagem. E a condição de possibilidade da linguagem é - como mostra o parágrafo 34 de Ser e tempo - o discurso (Rede) (Heidegger, 1977: 213). Este último é um momento constitutivo do processo hermenêutico antepredicativo: o discurso desempenha a função de articular os significados, os quais são depois expressos na comunicação linguística. Consequentemente, podemos dizer que a ausência de linguagem, típica da angústia, assinala uma suspensão da função do discurso.

O discurso articula habitualmente o fenomenal num contexto de significância, numa Bewandtnisganzheit (Heidegger, 1977: 112) que se refere às possibilidades do Dasein - uma totalidade que, precisamente na angústia, como já dissemos, se subtrai. A possibilidade de se exprimir em palavras se funda naquela prévia totalidade de significados que são articulados pelo discurso. Deste ponto de vista, a palavra é solidária com a Bewandtnis, ou seja, com a forma significativa na qual os fenômenos se mostram ao Dasein que se projeta em possibilidades. A falta de palavra, que ocorre na angústia, está 
estritamente conectada com o colapsar do contexto de significância significância que é o resultado da atividade conjunta da compreensão e do discurso. Resumindo, a experiência antepredicativa da angústia não é somente caracterizada por uma suspensão da compreensão, mas também por uma falta de atuação do discurso. Nesta experiência antepredicativa é suspenso o processo hermenêutico na sua totalidade.

Esta última consideração permite mostrar mais uma vez o sentido radical em que a angústia é antepredicativa: não somente porque, nesta condição, o homem é incapaz de exprimir-se numa linguagem predicativa, isto é, em discursos abstratos e teoréticos, mas também porque é privado da linguagem enquanto tal, em razão de uma suspensão provisória do discurso. Neste sentido, o antepredicativo é aqui sinônimo de não-linguístico e nãodiscursivo.

Mostramos que a angústia não tem um caráter discursivo nem linguístico. Deste ponto de vista, esta disposição afetiva fundamental é nãopredicativa. Ora, em que sentido pode-se caracterizar a angústia também como ante-predicativa? E, além disso: em que sentido podemos explicar este caráter ante-predicativo da angústia como um caráter ao mesmo tempo pré-linguístico e pré-discursivo - que é um dos objetivos das considerações presentes? Devese precisar, em via preliminar, que a pré-linguisticidade não deve ser entendida aqui como uma condição de vida menos evoluída, na qual a capacidade linguística não está presente. É possível entender a pré-linguisticidade num sentido diferente, positivo e não negativo. Em nosso entendimento, os prefixos «ante-» e «pré-» assinalam que a angústia não é completamente privada de conexão com o âmbito do discurso, da linguagem e da predicação. $\mathrm{O}$ ponto decisivo aqui é que a angústia, em si mesma não-discursiva (e, portanto, nãolinguística e não-predicativa), funda, contudo, a possibilidade de uma nova articulação de significados, de uma nova compreensão e, consequentemente, de um dizer que leva em conta aquela experiência fundamental, de um dizer que dela traz inspiração e que se nutre dela.

O prefixo «pré-» põe em evidência esta função fundadora da angústia em relação à dimensão dos significados e das palavras que os exprimem. $\mathrm{O}$ «pré-» não designa um «menos», mas alude a uma potencialidade originária que só aguarda ser exprimida, compreendida, interpretada - e tudo isso com a consciência de que esta experiência pré-discursiva é irredutível à dimensão 
discursiva e linguística e, portanto, nunca pode ser fixada numa forma significativa unívoca e definitiva. O papel fundativo da angústia parece-nos evidente em Ser e tempo, onde ela representa aquela experiência reveladora que conduz o homem a uma compreensão mais autêntica de si mesmo e de seu mundo e, com isso, a um modo do dizer oposto ao «falatório» (Gerede). Igualmente, Heidegger evidencia no Posfácio $a$ «O que é metafísica?» que a ausência de linguagem caraterística da angústia é a «origem» (Herkunft) do dizer do pensador e do nominar do poeta (Heidegger, 1976a: 311-312). Na angústia, lá onde a capacidade discursiva e hermenêutica é suspensa, é fundada a possibilidade de nova discursividade e linguagem. $O$ aspecto «prélinguístico» indica, portanto, não apenas uma experimentada e temporária impotência a falar, mas também uma tensão ou pro-tensão, no homem angustiado, para uma posterior elaboração hermenêutica e linguística do que foi anteriormente experimentado de forma ainda não significativa.

\section{O destino do «antepredicativo» depois da Kehre e considerações finais}

O sentido que aqui atribuímos ao conceito de antepredicativo - caracterizado não apenas como pré-teorético, mas também como pré-linguístico - pode ser salientado referindo-se também ao contexto especulativo posterior das Contribuições à filosofia. No parágrafo 255 desta obra, Heidegger introduz a ideia do grande silêncio (große Stille), o qual é definido como «a viragem (Kehre)» entre o clamor (Zuruf) e a escuta (Zugehör) (Heidegger, 1989: 407408). Se o grande silêncio é o acontecimento no qual o homem é chamado pela voz do Ser, esta chamada pode acontecer, para Heidegger, numa experiência concreta. Na mesma passagem textual onde é definido o grande silêncio, Heidegger faz referência à análise, conduzida na parte inicial da obra, da disposição emotiva fundamental da «retenção» (Verhaltenheit) ${ }^{16}$ e a um aspecto

${ }^{16} \mathrm{O}$ conceito de Verhaltenheit tem um papel central nas Contribuições à filosofia, sendo que ela designa o fundamento da cura (Heidegger, 1989: 35) - cura (Sorge) com a qual Heidegger identificava em Ser e tempo a determinação unitária fundamental do Dasein. Se em Ser e tempo a «cura» representa o fundamento, ou seja, a condição de possibilidade de qualquer comportamento (Verhalten) ôntico do Dasein, nas Contribuições Heidegger remonta a um fundamento mais originário, mostrando como os comportamentos do Dasein são possibilidados, em última análise, pela retenção. A retenção pre-dispõe cada comportamento do Dasein. O trato comum entre a 
que a caracteriza, o silêncio. Esta análise ocupa principalmente o parágrafo 13 das Contribuições (Heidegger, 1989: 36). O fato de que, para explicar o grande silêncio, Heidegger faça referência à análise do parágrafo 13 torna legítima a suposição de que o fenômeno da retenção representa uma situação ôntica, uma experiência na qual o grande silêncio acontece concretamente, ou seja, na qual o homem se sente chamado pelo Ser.

O que caracteriza a retenção, ou, pelo menos, um aspecto desta disposição emotiva, é, como mostra Heidegger no mesmo parágrafo 13, uma condição na qual, como já na angústia, nos sentimos privados da palavra. É numa tal condição que o Dasein é chamado pelo Ser, ou seja, faz experiência do Ser. O grande silêncio, entendido como relação instantânea do homem com o Ser, ocorre nesta condição na qual a palavra nos falta. Heidegger a descreve assim:

A palavra nos falta; não como uma ocorrência ocasional, junto à qual não teria lugar um discurso e um enunciado realizável e onde apenas o enunciar e o redizer o que já foi dito e o que é dizível não são levados a termo, mas originariamente. A palavra não ganha ainda de modo algum a palavra, por mais que ela chegue ao primeiro salto por meio de tal corte. O que corta a palavra é o acontecimento apropriador enquanto aceno e acometimento do Ser (Heidegger, 1989: 36. Trad. Casanova [modificada]: 39).

O que é aqui descrito é uma condição análoga àquela da ausência de linguagem (Sprachlosigkeit) característica da angústia. Heidegger descreve uma situação em que não é esta ou aquela palavra que nos falta, mas a linguagem como tal. Heidegger precisa que esta condição provisória de mudez não é o silêncio intencional de quem não fala o que é ainda exprimível, mas de quem experimenta uma momentânea incapacidade de articular significados numa forma linguística. Trata-se aqui, como no caso da angústia, de uma experiência não-linguística.

Um último ponto deve ser ressaltado. No final desta passagem citada do parágrafo 13, Heidegger afirma que esta experiência é a condição inicial

Verhaltenheit e o Verhalten é o momento do Halt. Heidegger escreve, na Carta sobre o humanismo, que o sustenho (Halt) de cada comportamento (Verhalten) é oferecido pela verdade do Ser (cf. Heidegger, 1976a: 361). Mas esta última, como mostram as Contribuições, só pode ser acolhida numa disposição de Verhaltenheit. 
para a possibilidade de uma denominação originária (Heidegger, 1989: 36). Similarmente, no parágrafo 255, Heidegger esclarece que o grande silêncio é a origem da linguagem (Heidegger, 1989: 408). Não poderemos acrescentar mais detalhes a este respeito ${ }^{17}$; queremos apenas tentar uma avaliação conclusiva do fenômeno do grande silêncio ${ }^{18}$. Mostramos, por um lado, que esta figura do pensamento heideggeriano tardio sugere a idéia de que o homem pode ter uma experiência privilegiada do Ser numa condição não-linguística. Por outro lado, apontamos para a afirmação heideggeriana segundo a qual o grande silêncio representa a origem da linguagem. Estas duas considerações permitem interpretar, enfim, o grande silêncio como uma experiência antepredicativa. Não se trata simplesmente de dizer que o grande silêncio é uma experiência ou relação ainda não teorética, intelectual e abstracta, mas de destacar um sentido mais radical do conceito de antepredicativo. Em particular, o grande silêncio pode ser qualificado como «antepredicativo» enquanto é pré-linguístico. Por sua vez, a pré-linguisticidade do grande silêncio indica dois aspectos. Em primeiro lugar, ela assinala que este silêncio circunscreve um âmbito nãodiscursivo e, portanto, não-linguístico. Em segundo lugar, o grande silêncio pode ser definido como pré-linguístico no sentido em que funda a possibilidade da linguagem do Dasein - no sentido em que é, como sugere o próprio Heidegger, a «origem» da linguagem ${ }^{19}$.

Esta breve consideração do fenômeno do grande silêncio deve ser considerada juntamente às indicações que já coletamos relativamente à vivência do pré-mundano (no curso de 1919) e à angústia dos anos 1927 e 1929. Todas estas indicações atestam que é possível encontrar, no percurso heideggeriano inteiro, passagens textuais que oferecem uma visão diferente sobre o fenômeno do antepredicativo. O antepredicativo não é somente sinônimo de hermenêutico - como aparece de maneira evidente seguindo, de maneira filológica, as etapas da sua história conceitual -, mas esconde em si

\footnotetext{
${ }^{17}$ Para uma análise mais detalhada veja-se: Pasqualin, 2017.

18 Sobre o silêncio (Stille) como elemento que possibilita a linguagem verbal (e sobretudo a linguagem poética) e é, ao mesmo tempo, sempre excedente a esta dimensão veja-se: Smith 2013: em particular 61-99.

19 Estes aspectos são tematizados mais amplamente em nosso ensaio Das Vorprädikative als das ,Pathische“: Ein Vergleich zwischen der „großen Stille“ bei Heidegger und dem ,, Sagen“ bei Lévinas em Pasqualin 2020: 237-264.
} 
uma dimensão de sentido mais profunda, a qual pode ser resumida, de maneira geral, com o termo «pré-hermenêutico» ou «pático». Antepredicativo não é somente aquele modo de descobrimento que acontece no meio do processo hermenêutico, isto é, na atuação da compreensão e na articulação discursiva e linguística dos significados. Antepredicativa pode ser definida também uma aproximação ainda não hermenêutica ao real - uma aproximação, ou um contato, que é possibilitada pelo outro existencial fundamental, pela Befindlichkeit/afetividade, a qual continua ativa mesmo quando a compreensão, o discurso e a linguagem são transitoriamente suspensos.

Tanto a angústia, na primeira fase do pensamento heideggeriano, quanto a retenção, no contexto posterior, mostram a possibilidade de um contato pré-linguístico com o Ser e, de forma mais geral, com o âmbito fenomenal - um contato que pode ser definido como pático, pelo fato de que a capacidade discursiva do Dasein (ou seja, de formação e articulação semântica) é temporariamente suspensa. Se na angústia e na retenção não é o discurso (cooriginário com a compreensão) o canal privilegiado de acesso ao fenomenal, deve ser o outro existencial fundamental, a Befindlichkeit, a oferecer este contato. Os exemplos da angústia e da retenção mostram como o Dasein possa ter um contato pré-linguístico com o fenomenal, estabelecido por meio da afetividade, e designável, portanto, como «pático». O nosso objetivo foi de mostrar como este contato pático configura uma dimensão antepredicativa mais originária da dimensão hermenêutica. É verdade que na primeira fase do seu pensamento Heidegger identifica explicitamente o antepredicativo com o hermenêutico. Contudo, pode se mostrar como o processo hermenêutico está fundado na abertura pática da afetividade. Esta tese - a tese acerca da primazia ontológica da afetividade ${ }^{20}$ - tem como consequência que o contato pático acaba por ser o antepredicativo originário. O prefixo «ante-» enfatiza a anterioridade ontológica do pático: este último não é apenas anterior à capacidade teorético-predicativa, mas também à capacidade discursiva enquanto tal.

Desta maneira, o presente ensaio esboça, com base nos textos heideggerianos, a tese de uma origem pática da linguagem. Contudo, não pretendemos avançar a hipótese que a capacidade discursiva deriva da

${ }^{20}$ Veja-se a nota 14. 
afetividade, como se ela representasse uma simples evolução do relacionamento pático originário. Pelo contrário, a afetividade e a capacidade hermenêutica-discursiva são estruturas cooriginárias do Dasein ${ }^{21}$ : ou seja, desde o átimo no qual o Dasein vem ao mundo, ele é um befindliches und verstehendes Dasein. A nossa idea não é demonstrar que os significados surgem ou emergem - como num processo evolutivo interno - de algo não significativo (o que estabeleceria uma relação genética entre duas ordens não homogêneas), mas que os significados, que são produtos da nossa capacidade hermenêutica, se baseiam na experiência pática, ou seja, na experiência ôntica e ontológica do fenomenal na sua consistência originária puramente fatual. A estruturação semântica - e depois linguística - do dado fenomenal pressupõe que este dado seja previamente descoberto como algo dado, como algo não constituído, como uma alteridade que não é posta pelo projeto do Dasein, mas à qual o Dasein está passivamente submetido. O compreender e o articular semântico (discursivo e linguístico) pressupõem, portanto, um originário estar-exposto a algo «que é» e do qual nós não somos os autores.

\section{Referências}

Apel, K.-O. (1975). Die Idee der Sprache in der Tradition des Humanismus von Dante bis Vico. Bonn: Bouvier.

Costa, V. (2015). «Esperienza antepredicativa e adeguazione in Heidegger». Rivista di Filosofia Neo-Scolastica, 107 (3), 537- 555.

〈https://doi.org/10.1400/236628〉

Dreyfus, H.L. (1991). Being-in-the-World. A Commentary on Heidegger's Being and Time, Division I. Cambridge (Mass.): The MIT Press.

Figal, G. (2013). Martin Heidegger. Phänomenologie der Freiheit, Tübingen: Mohr Siebeck.

Golob, S. (2014). Heidegger on Concepts, Freedom and Normativity, Cambridge: Cambridge University Press.

Heidegger, M. (2000). Vorträge und Aufsätze, GA 7, ed. F.-W. von Herrmann. Frankfurt am Main: Klostermann.

${ }^{21}$ Befindlichkeit e Verstehen são por Heidegger existencias fundamentais coóriginarios (gleichursprünglich) (Heidegger, 1977: 177). 
Heidegger, M. (1999). Die Idee der Philosophie und das Weltanschauungsproblem. In: Zur Bestimmung der Philosophie, GA 56/57, ed. B. Heimbüchel. Frankfurt am Main: Klostermann, 1-117.

Heidegger, M. (1997). Besinnung, GA 66, ed. F.-W. von Herrmann. Frankfurt am Main: Klostermann.

Heidegger, M. (1989). Beiträge zur Philosophie (Vom Ereignis), ed. F.-W. von Herrmann. Frankfurt am Main: Klostermann. Trad. M.A. Casanova. Contribuições à filosofia (Do acontecimento apropriador). Rio de Janeiro: Editora Via Vérita, 2014.

Heidegger, M. (1983). Die Grundbegriffe der Metaphysik. Welt-Endlichkeit - Einsamkeit, GA 29/30, ed. F.-W. von Herrmann. Frankfurt am Main: Klostermann.

Heidegger, M. (1978). Metaphysische Anfangsgründe der Logik im Ausgang von Lebniz, GA 26, ed. F.-W. von Herrmann. Frankfurt am Main: Klostermann.

Heidegger, M. (1977). Sein und Zeit, GA 2, ed. F.-W. von Herrmann. Frankfurt am Main: Klostermann. Trad. port. de F. Castilho, Ser e tempo. Petrópolis: Editora Vozes.

Heidegger, M. (1976). Logik. Die Frage nach der Wahrheit, GA 21, ed. W. Biemel. Frankfurt am Main: Klostermann.

Heidegger, M. (1976a). Wegmarken, GA 9, ed. F.-W. von Herrmann. Frankfurt am Main: Klostermann.

Heidegger, M. (1975). Die Grundprobleme der Phänomenologie, GA 24, ed. F.-W. von Herrmann. Frankfurt am Main: Klostermann.

Heidegger, M. (1963). Aus der Erfahrung des Denkens, GA 13, ed. H. Heidegger. Frankfurt am Main: Klostermann.

von Herrmann, F.-W. (2000). Hermeneutik und Reflexion. Der Begriff der Phänomenologie bei Heidegger und Husserl. Frankfurt am Main: Klostermann. [LEP:

Inkpin, A. (2016). Disclosing the World: On the Phenomenology of Language. Cambridge (MA): MIT Press.

Kisiel, T. (1992). «Das Kriegsnotsemester 1919: Heideggers Durchbruch zur hermeneutischen Phänomenologie». Philosophisches Jahrbuch, 99, 105-122. 
Lafont, C. (1994). Sprache und Welterschließung. Zur linguistischen Wende der Hermeneutik Heideggers. Frankfurt am Main: Suhrkamp.

Pasqualin, C. (2017). «Considerazioni sull'origine 'patica' del linguaggio attraverso i testi heideggeriani». Logoi. Rivista di Filosofia, 3 (9), 276-291.

Pasqualin, C. (2015). «Der „pathische“ Grund des Hermeneutischen: Die ontologische Priorität der Befindlichkeit vor dem Verstehen». Heidegger Studien, $\quad 31$ 129-151. 〈https://doi.org/10.5840/heideggerstud2015316

Pasqualin, C., Sforza, A. (ed.) (2020). Das Vorprädikative. Perspektiven im Ausgang von Heidegger. Freiburg: Alber Verlag.

Smith, D.N. (2013). Sounding/Silence. Martin Heidegger at the Limits of Poetics. New York: Fordham University Press.

Tugendhat, E. (1976). Vorlesungen zur Einführung in die sprachanalytische Philosophie. Frankfurt am Main: Suhrkamp.

Vigo, A.G. (2012), «Categorías y experiencia antepredicativa en el entorno de Sein und Zeit». Studia Heideggeriana, 2, 71-128.

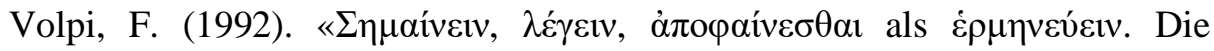
Ontologisierung der Sprache beim frühen Heidegger im Rückgriff auf Aristoteles». In: E. Rudolph, H. Wismann (ed.). Sagen, was die Zeit ist. Analysen zur Zeitlichkeit der Sprache. Stuttgart: Metzler, 21-42. 